\title{
Contemporary Trend of Drug Abuse among In-School Adolescents in Kwara State, Nigeria
}

\author{
Bolu-Steve, Foluke Nike
}

\begin{abstract}
Presently, drug abuse has become a societal problem with its prevalence being found among adolescents in Nigeria. This study focuses on the contemporary trend of drug abuse among in-school adolescents in Kwara State, Nigeria. The study employed the use of a descriptive survey design. One hundred respondents were chosen for the study through the use of a simple random sampling technique from the three Senatorial districts of Kwara State. In total, three hundred adolescents participated in the study. The respondents were stratified on the basis of age and gender. In order to ascertain the validity of the instrument of this study, copies of the questionnaire were given to experts and lecturers in related fields for vetting. A reliability index of 0.75 was obtained using a test-retest method. The instrument used for this study was tagged "Trends of Drug Abuse Questionnaire" (TDAQ). The outcome of this research revealed that a significant difference existed in in-school adolescent's perception on the contemporary trend of drug abuse based on age. However, on the basis of gender, the respondent's perceptions were similar. Given these results, it is recommended that drug refusal skills as well as drug education be incorporated into students' orientation programs.
\end{abstract}

Key words: drug abuse, in-school adolescents, Kwara State

Foluke Nike Bolu-Steve, Ph.D., is a Lecturer in the Department of Counsellor Education, University of Ilorin, Nigeria. She obtained her Doctor of Philosophy (2013) at the University of Ilorin, Nigeria in Educational Guidance and Counselling. She is a member of the Counselling Association of Nigeria and the Association of Professional Counsellors in Nigeria. As a professional teacher, she is a registered member of the Teachers' Registration Council of Nigeria (TRCN). Some of her publications include: Bolu-Steve, F.N. Olawuyi, B.O \& Shaba, R.M (2015). Child rearing and career performance of working-class women in Nigeria. African Journal of Cross Cultural and Sports Facilitation (AJCPSF) 1225-1237; Bolu-Steve, F.N, Adegoke, A.A and Adeboye, A. (2017). Counsellors Perception on enhancing girl-child education in Kwara State, Nigeria. The Counsellor, 36(2), 82-98, and Adebayo, D. O, Ninggal, M, T, and Bolu-Steve, F. N. (2020). Relationship between Demographic Factors and Undergraduates' Cyberbullying Experiences in Public Universities in Malaysia. International Journal of Instruction, 13(1), 901-914. 


\section{Introduction}

A drug is any chemical substance that affects the physical or psychological lifestyle of a person and when such a substance is ingested, it alters body function (Carla, 2002). Drug abuse is the misuse of illegal and legal drugs. Legal drugs are those that are prescribed by medical practitioners while illegal drugs are purposively controlled by the National Drug Law Enforcement Agency (NFADAC) so that it will not be abused. Muazu and Aliyu (2008) submitted that drug abuse is actually the intake of drugs without regard to medical prescription. This condition affects the neurological function of the users. Continuous use of drugs can lead to dependence. Drug addiction is the constant need and craving for drugs. This is characterized by drug-seeking habits and its use is compulsive and difficult to control, despite the harmful effects (National Institute on Drug Use, 2016). It is important to note that the constant use of drugs can lead to a drug obsession. Drug addiction is often referred to as a substance disorder or relapsing disease. This is because it affects the brain. Such a habit can reoccur several times (Nora \& Volkow, 2015).

When there is high substance dependency, the urge for drug intake becomes high and the crave to seek such drugs increases. The process and ways people get addicted to drugs varies. For instance, it has been discovered that painkillers have a higher risk of causing addiction than any other drug (Mayo Clinic, 2017). Those addicted to drugs always have intense urges to use the substance despite its effects (United Nations Office on Drugs and Crime, UNODC 2007). Some of the conventional drugs that are commonly abused are alcohol, cannabis, hemp, heroin or a mixture of different herbs which is commonly called sepe in Nigeria. The biological composition of a person, the environment, peer influence, mental health disorder, early use of drugs, stress, and family history of drug dependence can predispose an adolescent to drug abuse (World Drug Report, 2014). According to the Centre for Disease Control (2007), 15\% of adolescents between the ages of 12 and 18 in America use drugs on a regular basis and that the number of adolescents who are into drugs has risen to about 24.6 million.

A World Drug report (2005) revealed that Nigerians are major users of illegitimate drugs. NAFDAC (2008) explained that the number of youths who are into drugs in the Northwest of Nigeria is about $37.47 \%$, the South West is at $17.32 \%$, the North central is at $11.71 \%$, while in the North East, the percentage is at 8.54. Odo (2015) explained that many adolescents are into drugs and that it has become a universal problem. NAFDAC (2002) reported that the most commonly abused drug is alcohol as $61 \%$ of the Nigerian population drinks alcohol. In summary, the use of drugs is a common phenomenon among the youth of today. Atoyebi and Atoyebi (2013) noted that some of the common drugs abused by adolescents include, alcohol, tobacco, cannabis amphetamines, inhalants, sedative drugs, heroin, and cocaine.

In contemporary times, drug abuse has become a societal problem. This is prevalent among the adolescents of Nigeria. Drug use among youths is now a matter of great concern (Acolagbe, 2005). Adolescents believe that alcohol and coffee are the preference of the older generation while the huffing of tobacco and the use of other non-conventional drugs are the desires of youth in this current generation (Carla, 2002).

The government has promulgated some decrees in order to control the usage of drugs among youth. Decree 20 of 1998 banned smoking in public places. In the same vein, Decree 
48 of 1999 brought about the establishment of the National Drug Law Enforcement Agency. This was done in order to control the dangerous trend of drug abuse.

It is interesting to note that even though drug abuse has become prevalent among adolescents, the trend of drug use keeps changing (Awoyemi, 2009). In the past, addicts used fermented liquor such as ogogoro, burukutu and palm wine. Awoyemi (2009) indicated that smoking diverse stimulating plants and the chewing of some local products such as kola had been used for centuries. The trend of substance use changed drastically in Nigeria between 1970 and 1980 when cannabis seed was imported from India by war veterans after the Second World War. Substances such as heroin, cocaine, opioids, amphetamines and khat leaves, and morphine became common among the youth (Vangaurd, 2016).

Cocaine, in particular, is a drug that has been in high demand over the years. When ingested or snorted, such an individual becomes very high. Heroin, amphetamines, and narcotics are the drugs which are most widely used among Nigerian youths for mood alteration (Osodi,Aina and Onajole, 2010)

By the year 1990, non-conventional inhalant substances began to reign in Nigeria. Substances such as kerosene volatile solvents, rubber solutions, correction fluid, aerosols, nail polish remover, petrol and gasoline, and butyl nitrate products became common among youth. According to Danjuma (2015), youth make use of pit toilet/soak away fumes (bio generic gas), gun powder, lizard dung especially the whitish part, goskolo (a concoction of unimaginable harm), gadagi (a substance resembling tea leaves), robin blue powder cocktails, and pharmaceutical products such Rohypnol, Codeine, Tramadol, and cough syrup mixed with soft drinks. These products are steadily increasing and becoming more popular among the youth as compared to using alcohol (Vanguard, 2016).

The inhaled substances such as Moringa leaves, hydrogen sulphide gas (sewer gas, tear gas and toilet effluent are now the most desired substances among youths and adolescents. Youths also sniff cocaine and heroin which has been a staple drug among youth over the years. Opium is a painkiller but at the same time, it can induce sleep. Because of this effect, many adolescents are addicted to it. Medically prescribed drugs like Paracetamol, Aspirin, Alabuku, Antibiotics and sedatives drugs are constantly abused nowadays (Olubi, 2017). Many adolescents are addicted to ogogoro, sepe which Nigerians calls native local gin. They are not permitted to be on-counter for sale, but they are available everywhere. The sales of these substances are common among people who sell herbs in Kwara State.

The National Institute on Drugs (2017) raised an alarm on the introduction of a new drug called "Gulf Coast" with the street name "Grey Death". The substance contains opioids and it is stronger than heroin. The Centre for Disease Control and Prevention (CDC) (2017) has explained that the current high usage of fentanyl-related overdoses has resulted in many deaths.

Traditionally, the stereotype users of drug use were largely males. Poole and Dell (2005) observed that this trend has changed and that recently, studies have revealed the involvement of females in drug misuse. Substance Abuse and Mental Health Services Administration (SAMHSA, 2005) confirmed that 15 million women use drugs for many reasons. Labo (2017) reported that the Nigerian president wife recently raised an alarm on the high usage of drugs among youths, especially women, in the North East of Nigeria. Presently, it has been discovered 
that the use of some certain drugs are higher among females than males (Johnston, O'Malley, Bachman, \& Schulenberg, 2007). Carla (2002) noted male and female adolescents' indulgence in the use of drugs is the common vogue.

Problem

Decree 20 of 1984 makes drug-pushing an offence, punishable by death, in Nigeria and yet, Fayombo and Aremu (2000) confirmed that the prevalence of drug use is high among adolescents. In the same vein, the United Nation Office of Drug Abuse and Crime (UNODC,2007) revealed that drug abuse has led to diverse health problems and at the same time increased the rate of crime in Nigeria. The uncontrollable compulsive desire for drugs and the presence of ill health among the youth of today calls for serious attention. Labo (2017), in particular, noted that there is a high prevalence of drug use in the North Eastern part of Nigeria. Incidentally, Kwara State is one of the states in the Northern side of the country. In 2013, about 3,271 drug addicts were successfully treated and counselled in NDLEA.

Chen, Sheth, Elliott and Yeager (2004), Hamisu and Othman (2014), Atoyebi and Atoyebi, (2013), Durotoye (2003) studied the prevalence of substance use and drug related issues. To the researcher's best knowledge, these aforementioned did not focus on the contemporary trends of drug abuse among adolescents.

\section{Research Questions}

1. What are the drugs that are contemporary abused among in-school adolescents in Kwara State?

2. How prevalent is drug abuse among in-school adolescents in Kwara State?

\section{Research Hypotheses}

1. There is no significant difference in the contemporary trend of drug abuse among inschool adolescents in Kwara State based on age.

2. There is no significant difference in the contemporary trend of drug abuse among inschool adolescents in Kwara State based on gender.

\section{Methodology}

\section{Sample and Sampling Procedures}

The research design adopted for this study was a descriptive survey type. Ibrahim, Landu and Opadokun (2004) noted that descriptive survey research employs questionnaire 
and/or interviews in order to determine the opinion, attitudes, preference and perception of a person's interest. In view of this, it was decided that a descriptive survey method was the most appropriate method for this study.

The respondents for this study consisted of all in-school adolescents in Kwara State. One hundred respondents were picked for the study through the use of a simple random sampling technique from the three Senatorial districts of Kwara State. In total, three hundred adolescents participated in the study. The respondents were stratified on the basis of age and

26

gender. The validity of the instrument of this study was also ascertained as copies of the questionnaire were given to experts and lecturers in related fields for vetting. A reliability index of 0.75 was obtained using a test-retest method.

\section{Results}

\section{Research Question 1}

What are the drugs that are contemporary abused among in-school adolescents in Kwara State?

Table 1

\section{Percentages, Mean and Rank Order Analysis on Current Trend of Drug Use among In-School}

\begin{tabular}{|c|c|c|c|c|c|}
\hline \multicolumn{2}{|c|}{ Trend of Drug use } & Frequency & \multirow{2}{*}{$\begin{array}{l}\text { Mean } \\
\\
1_{\text {st }}\end{array}$} & \multirow{2}{*}{$\begin{array}{r}\text { Rank } \\
\text { A }\end{array}$} & \multirow{2}{*}{ Remark } \\
\hline Tramadol & $218(72.7 \%)$ & 1.77 & & & \\
\hline Alcohol & $172(56.3 \%)$ & 1.61 & 2 nd & A & \\
\hline Local gin ( e.g & & & & & \\
\hline $\begin{array}{l}\text { Sepe, ogogoro, } \\
\text { mixture of herbs) }\end{array}$ & $169(56.3 \%)$ & 1.60 & $3 \mathrm{rd}$ & A & \\
\hline Cough mixture & $161(53.6 \%)$ & 1.58 & $4_{\text {th }}$ & A & \\
\hline Tobacco & $153(51.0 \%)$ & 1.55 & 5 th & A & \\
\hline Petrol & $160(53.3 \%)$ & 1.53 & 6 th & A & \\
\hline Glue & $155(51.7 \%)$ & 1.52 & $7_{\mathrm{th}}$ & A & \\
\hline Nail polish & $137(45.7 \%)$ & 1.50 & 8 th & A & \\
\hline Valium & $142(47.3 \%)$ & 1.47 & $9_{\text {th }}$ & A & \\
\hline Gas & $142(47.3 \%)$ & 1.47 & $9_{\text {th }}$ & $\mathrm{R}$ & \\
\hline Gun powder & $121(40.3 \%)$ & 1.44 & $11^{\text {th }}$ & $\mathrm{R}$ & \\
\hline Caffeine & $111(33.7 \%)$ & 1.37 & $12^{\text {th }}$ & $\mathrm{R}$ & \\
\hline Codeine & $100(37.0 \%)$ & 1.37 & $12^{\text {th }}$ & $\mathrm{R}$ & \\
\hline Rehypnol & $98(32.7 \%)$ & 1.37 & $12^{\text {th }}$ & $\mathrm{R}$ & \\
\hline
\end{tabular}


Lighter fluid

$102(34.6 \%)$

1.34

$15^{\text {th }}$

R

Marijuana

$102(34.6 \%)$

1.34

$86(28.0 \%)$

1.29

$84(28.0 \%)$

1.28

$15^{\text {th }}$

$17^{\text {th }}$

$\mathrm{R}$

Heroin

57 (19.0\%)

1.19

$18^{\text {th }}$

Amphetamines

$42(14.0 \%)$

1.14

$19^{\text {th }}$

Cannabis

(

$20^{\text {th }}$

$\mathrm{R}$

Standard Reference Mean $=1.5 ; \mathrm{A}=\mathrm{Accept} ; \mathrm{R}=$ Reject

27

Results from Table 1 revealed the trend of drug use among adolescents. It is observed that Tramadol, alcohol and local gin ranked as the top three among the list of drugs that are currently being used among adolescents with a mean score of 1.77, 1.61 and 1.60 respectively. However, Cocaine, Amphetamines and Cannabis were the least drugs used with mean scores of $1.28,1.19$ and 1.14 respectively.

\section{Research Question 2}


How prevalent is drug use among in-school adolescents?

Table 2

Prevalence of Drug Use among In-School Adolescents

\begin{tabular}{llcc}
\hline & & Yes (\%) & No (\%) \\
\hline 1. & Have you seen adolescents taken drug? & $227(75.7)$ & $73(24.3)$ \\
2. & Do adolescents in your area have easy access to drug? & $129(43.0)$ & $171(57.0)$ \\
3 & Have you ever taken drug? & $74(24.7)$ & $226(75.3)$ \\
4. & Are there adolescent drug addicts in your area? & $141(47.0) 159(53.0)$ \\
5. & Do you belief that drug usage is high among adolescents? $210(70.0) 90(30.0)$ \\
\hline
\end{tabular}

Results from Table 2 revealed that 227 (75.7\%) of the respondents that participated in the study had seen adolescents taking drugs while 73 (24.3\%) had not seen any adolescents taking drugs. $129(43.0 \%)$ of the respondents attested that adolescents have easy access to drugs in their areas while $171(57.0 \%)$ stated that adolescents do not have easy access to drugs. Furthermore, $74(24.7 \%)$ of the respondents have used drugs while $226(75.3 \%)$ claimed that they had not taken drugs.

\section{Hypothesis One:}

There is no significant difference in the contemporary trend of drug abuse among inschool adolescents in Kwara State based on age.

Table 3

Analysis of Variance (ANOVA) Result on the Contemporary Trend of Drug Abuse

\begin{tabular}{lllllll}
\hline Source of & Sum of & df & Mean & Calc. & Crit. & p-value \\
Variance & Squares & & Squares & F-ratio & F-ratio & \\
\hline
\end{tabular}




\begin{tabular}{lllllll}
\hline Between Group & 18.3 & 2 & 9.4 & $6.60 *$ & 3.00 & .002 \\
Within Group & 411.5 & 297 & 1.39 & & & \\
Total & 429.8 & 299 & & & & \\
\hline $\mathrm{p}<0.05$ & & & & &
\end{tabular}

Table 3 above shows that the calculated F-ratio of 6.60 is greater than the critical Fratio of 3.00 with a corresponding p-value of .002 which is less than 0.05 alpha level of significance. Hence, the null hypothesis is therefore rejected.

Table 4

DMRT Showing the Magnitude of Difference in the Trend of Drug Use Based on Age

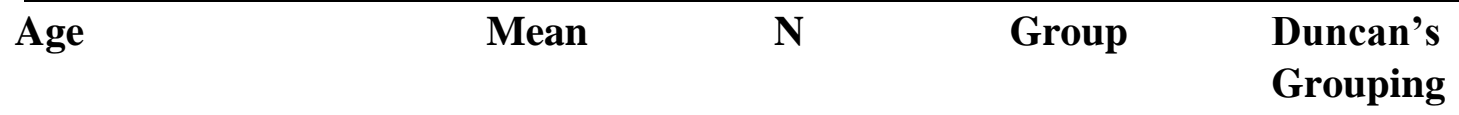

\begin{tabular}{lllll}
\hline 20 years old & 6.43 & 7 & 2 & $\mathrm{~A}$ \\
$17-19$ years old & 6.74 & 23 & 3 & $\mathrm{~B}$ \\
$* 13-16$ years old & 7.48 & 270 & 1 & $\mathrm{~B}$ \\
\hline
\end{tabular}

Results in Table 4 shows the magnitude of difference in the trend of drug abuse based on age. It is observed that all the age groups contributed to the differences. However, it can be inferred that group 1 with the highest mean score of 7.48 contributed more to the difference noted in the ANOVA table.

\section{Hypothesis Three}

There is no significant difference in the contemporary trend of drug abuse among inschool adolescents in Kwara State based on gender.

Table 5

Means, Standard Deviations and t-value on the Trend of Drug Abuse 


\begin{tabular}{llllllll} 
Gender & N & Means & Std. Dev & df & $\begin{array}{l}\text { Cal. t- } \\
\text { value }\end{array}$ & $\begin{array}{l}\text { Crit. t- } \\
\text { value }\end{array}$ & p.-value \\
\hline Male & 149 & 7.45 & 1.33 & & & & \\
Female & 151 & 7.34 & 1.05 & 298 & 0.76 & 1.96 & .448 \\
\hline
\end{tabular}

Table 5 shows that the calculated t-value of 0.76 is less than the critical t-value of 1.96 with a corresponding p-value of 0.448 which is greater than 0.05 alpha level of significance. As such, the null hypothesis is therefore not rejected.

\section{Discussion}

The rate of drug use among in-school adolescent has become a source of concern to stakeholders. The reason for this concern is the dramatic change in the trend of drug usage among adolescents. Many of the respondents confirmed that they have seen a number of adolescents who are into drugs. Likewise, they agreed that drug usage is high among adolescents. In line with these findings, Aworanti (2006) also observed that the high rate of the involvement of youth in drug use is alarming. Bolu-Steve (2015) confirmed that the major challenges confronting adolescents in this $21^{\text {st }}$ century is the issue of drug usage.

In order to curb this menace, NDLEA was established. Durotoye (2003) explained that most youths actually have access to drugs since they are affordable and easy to get. According to NDLEA, the drugs that were seized in 2013 weighed about $339,968 \mathrm{~kg}$ which is approximately equal to about N34 billion Naira when compared with the street value. This study shows that Tramadol, alcohol and local gin such as sepe \& ogogoro ranked as the most current drugs used among adolescents. Sepe is local drink that is commonly used among adolescents in Kwara State. It is made up of different substances mixed together that alters the body's functionality. Adamson (2015) carried out a study on a descriptive national survey of substance use in Nigeria. The researcher discovered that a large number of the respondents who participated in the study had heard about the non-conventional use of substances. The researcher revealed that the trend in drug use has changed over time and that there is a departure from the conventional use of cocaine, alcohol, and palm wine to non-conventional substances.

Many adolescents who are into drugs do not actually understand the effects while others do not consider the consequences because of the satisfaction they derive from it. Steve, Nadra and Mark (2011) revealed drug abuse has become a social problem in Nigeria while Osunde (2006) noted that drug abuse causes brain and liver damage, depression, family disintegration, and can lead to criminal offences.

Male and female respondents did not differ in their perceptions. This is because drug use is no longer gender stereotyped and an adolescent's current style of using drug has changed over the decades. Brewer and Potenza (2008) explained that currently, recreational drugs are used for various reasons such as modifying emotions or inducing a state of alertness. Carla

(2002) discovered that the consumption of substance use among women has increased over the centuries and that the use of drugs has taken on a new dimension from what it used to be in the 
past. This might be as a result of the fact that people believe that men and women use drugs for different reasons. Culturally, females are not expected to abuse drugs but this trend has changed over time. Obot's (2003) study has clearly revealed that the high rate of drug use among females has resulted in a lot of damage.

Results differed based on age. The dissimilarities in perceptions could be as a result of the fact that age has a way of influencing the way people view issues. Those in their early and late adolescence are likely to perceive issues in a different way. The level of one's exposure to information also influences people's perception. The current trend in the use of drugs among adolescents in secondary school is not an unusual phenomenon. The drugs that are in vogue among students are coffee, inhalant substances, analgesics such as Tramadol while Indian hemp, alcohol and cigarettes are abused sparingly (Adebowale et.al., 2013). Also, Muazu and Aliyu (2008) noted that drug abuse can lead to psychiatric problems such as schizophrenia.

\section{Conclusion}

The following conclusions were drawn from the study. Adolescents agreed that there is a high prevalence of drug use. The contemporary drug abused among adolescents at the current time is Tramadol, alcohol, and local gin called sepe, ogogoro (a mixture of different intoxicating herb). The respondents' gender did not influence their perception on the contemporary trend of drug abuse.

The result of this study has implications for counsellors who are in the helping profession. The trend in the use of drugs has change over time. The counsellor should also brace up with new inventive techniques of handling students with such challenges. The counsellor must be accessible to student's adolescents who needs to be counselled in this area.

\section{Recommendations}

1. School counsellors should update themselves with current information on the use of drugs. This will help them to educate adolescents on the negative impact of drug abuse.

2. Drug refusal skills, drug enlightenment, and new trends in the use of drugs should be included in students' orientation programs.

3. The government in conjunction with school authorities should mount aggressive campaigns on the indiscriminate use of drugs among adolescents in schools. 


\section{References}

Acolagbe, J. E. (2005). The youth and drugs abuse. A lecture delivered at the Annual Youth Convention of the Adventist Society in Benin City.

Adamson, T.A. Ogunlesi, A.O. Morakinyo O, Akinhanmi, A.O, Onifade, P.O, et al. (2015) Descriptive National Survey of Substance Use in Nigeria. Journal of Addict Research and Therapy 6:234. doi:10.4172/2155-6105.1000234

Adebowale, O., Olatona, O., Abiola, S. A., Oridota, T. D., Goodman, C. F. \& Onajole, J. (2013). knowledge, attitude and practice of drug abuse among public secondary school students in Lagos, Nigeria. International Journal of Psychology, 44 (5), 378-86.

Atoyebi, O. A. \& Atoyebi, E. O. (2013). Pattern of substance abuse among senior secondary school students in a South-Western Nigerian city. International Review of Social Sciences and Humanities, 4(2), 54-65.

Aworanti. I. R. (2006). Prevalence and patterns of drug abuse among students in Ila Local Government Area of Ogun state, Nigeria. Unpublished M.Ed dissertation, Department of Counsellor Education, University of Ilorin.

Awoyemi, R. I. (2009). Causes and consequences of drug abuse among in-school adolescents in Kwara state. Unpublished M.E.d dissertation, Department of Counsellor Education, University of Ilorin.

Bolu-Steve, F. N. (2010). Psychological factors responsible for substance abuse as perceived by students of tertiary institutions in Kwara State. Institute Journal of Studies in Education, 3(1\&2), 39-48.

Brewer, J.A, Potenza M.N. (2008). The neurobiology and genetics of impulse control disorders: Relationships to drug addictions. Biochemical Pharmacology. 75:63-75.

Carla, R. (2002). World drug report. International Journal of Drug Policy, 13 (3), 225-235.

Centre for Disease Control and Prevention (2007). Tobacco use and the health of young people. Retrieved 3/3/18 from http://www.cdc.gov/HealthyYouth/tobacco/facts.htm

Chen K, Sheth AJ, Elliott DK, Yeager A. (2004). Prevalence and correlates of past-year substance use, abuse, and dependence in a suburban community sample of high-school students. Addictive Behaviors. ;29: 413-423.

Danjuma, A. Adeleke, T. Sunday, O. Samaila, B. Silas, K. Solomon, S. \& Yashi, N (2015). Non-conventional use of substances among youths in Nigeria. Retrieved on 15/3/18 https://www.omicsonline.org/open-access/nonconventional-use-of-substancsamongyouth-in-nigeria-viewpoints-of-students-in-a-nigerian-tertiary-institution-216711681000311.php?aid=64176 
Durotoye, A.A. (2003). Prevalence and consequences of drug abuse among adolescents as perceived by secondary school students in Ilorin metropolis. Unpublished B.Ed thesis in the Department of Counsellor Education, University of Ilorin.

Emerging Trend Bulletin (2017). Potent new opioid/opiate compound known as Grey Death .Retrieved from https;//asset.documentcloud.org/document/3700907/ Grey- DeathGCHIDTA 0517.pdf

Fatoye F.O, \& Morakinyo, O . (2002). Substance use amongst secondary school students in rural and urban communities in South Western Nigeria. East. Africa Medical Journal Vol 79: 299-305.

Hamisu, M. Ahmad Othman, T and Hooi Lian, L. (2014). Adolescent's and drugs abuse in Nigeria. Retrieved from http://www.iiste.org/Journals/index.php/JBAH/article/viewFile/10225/10434 www.

Johnston, L. D., O’Malley, P. M., Bachman, J. G., \& Schulenberg, J. E. (2007). The National survey results on drug use from the monitoring the future study, 1975-2006. Rockville, MD: National Institute on Drug Abuse.

Labo. F. (2017). Tackling drug abuse in Northern Nigeria. Retrieved from https://economicconfidential.com>features

Mayo Clinic (2017). Drug addiction and substance use disorder. Retrieved from https://www.mayoclinic.org/diseases-conditions/drugaddiction/symptomscauses/syc- 20365112

Muazu, A. A, Aliyu, A. A. (2008). Prevalence of psychoactive substance use among commercial motorcyclists and its health and social consequences in Zaria, Nigeria, Ann Africa Medcine., 7, 67 - 71.

National Center on Addiction \& Substance Abuse (2006). Women under the influence. Baltimore: The John Hopkins University Press.

National Drugs Law Enforcement Agency (2009). The World Drug Report 2014 has scored Nigeria higher than other African countries in cannabis seizure. Retrieved from http://www.ndlea.gov.ng/v1/?q=content/world-drug-report- 2014-nigeriarecordshighest-cannabis-seizure-africa-1

National Institute of drug abuse (2015). Nationwide Trends. Retrieved from https:/ /www.drugabuse.gov/publications/drugfacts/nationwide-trends

National Institute on Drug abuse (2017). Emerging trends and alerts. Retrieved from https://www.drugabuse.gov/drugs-abuse/emerging-trends-alerts. 
National Institute on Drug Use (2016). Understanding Drug Use and Addiction. Retrieved from https://www.drugabuse.gov/publications/drugfacts/understanding-druguseaddiction.

Nora D. \& Volkow, M. D. (2015). Drugs, brains, and behavior: The science of addiction Retrieved from https://www.drugabuse.gov/publications/drugs-brainsbehaviorscience-addiction/preface

Odo, S. C. (2017). Youths and drug abuse in Nigeria: challenge for the Nigeria churches Retrieved from http://www.unn.edu.ng/publications/files/youthanddruguse

Olubi.V. (2017). Top 12 most commonly misused/ abused drugs. Retrieved from hallmarknews.com>top-12- commonly-...

Oshodi, O. Y, Aina O. F, \& Onajole, A.T (2010). Substance use among secondary school students in an urban setting in Nigeria: prevalence and associated factors. Africa Journal of Psychiatry 13: 52-57.

Poole, N. \& Dell, C. A. (2005). Girls, women and substance use. Ottawa. Canadian Centre on Substance Abuse \& BC Centre for Excellence for Women's Health.

Substance Abuse and Mental Health Services Administration (SAMHSA) (2010). Substance abuse treatment admissions involving abuse of pain relievers: 1998 and 2008. Retrieved fromhttp://www.oas.samhsa.gov/2k10/230/230PainRelvr2k10.htm

Steve, S. Nadra, L. and Mark, G. (2011). Prevalence of the addictions: A problem of the majority or the minority? Retrieved from https: // www. Ncbi .nlm .nih. gov /pmc/articles/PMC3134413/

United Nations Office on Drug Control and Crime. (2010). World Drug Report. Vienna. 2010; UNODCP. from http://www.unodc.org/docs/treatment/CoPro/Web_Nigeria.pdf

United Nations Office on Drugs and Crime. (2007). Drug abuse and drug dependence treatment situation, in Nigeria. Retrieved from http://www.unodc.org/docs/treatment/CoPro/Web_Nigeria.pdf

Vangaurd (2016). Drug abuse and Nigerian youth. Retrieved from https://www.vanguardngr.com/2016/06/drug-abuse-and-nigerian-youths/

Weisman, T. (2002). Drug abuse and drug counseling: a case approach. New York: Jason Armson. 
Bolu-Steve 